\title{
A Rare Complication After Laparoscopic Gastric Banding: Connecting-Tube Penetration into the Hilus of the Kidney
}

\author{
R. Sneijder • H. A. Cense • M. Hunfeld • \\ R. S. Breederveld
}

Received: 11 September 2008 / Accepted: 19 November 2008/Published online: 17 December 2008

(C) The Author(s) 2008. This article is published with open access at Springerlink.com

\begin{abstract}
Laparoscopic adjustable gastric banding is a common operation for morbid obesity. Late complications mainly originate from either the injection port (dislocation, infection, leakage) or the gastric band (pouch dilatation, slippage, leakage, gastric erosion). Complications from the tube, connecting the port with the band, are rarely described. We report the penetration of a loose connecting tube into the kidney 8 months after removal of an infected injection port.
\end{abstract}

Keywords Gastric banding · Complication · Tubing · Migration

\section{Case Report}

A 46-year-old obese female patient presented herself with pain in the left side of her abdomen and back. Her medical history consisted of diabetes, hypercholesterolemia, appendectomy, and laparoscopic cholecystectomy. She had a laparoscopic adjustable gastric banding (LAGB) placement 1.5 years prior to presentation. This procedure was complicated after 10 months by dislocation of the reservoir, which was surgically refixed. Eight months before presentation, she developed an infection at the site of the reservoir necessitating removal of the reservoir and leaving the gastric band and tubing intraabdominal.

At presentation, the patients' pain was not related to movement, respiration, or oral intake. Her weight loss was

R. Sneijder $(\bowtie) \cdot$ H. A. Cense $\cdot$ M. Hunfeld $\cdot$ R. S. Breederveld Department of Surgery, Red Cross Hospital,

Vondellaan 13,

1942 LE, Beverwijk, The Netherlands

e-mail: rsneijder@rkz.nl
$18 \mathrm{~kg}$ in the last year despite removal of the reservoir. She also complained of pyrosis. Physical examination showed a cicatrical hernia in the left upper quadrant. There were no further abnormalities. Her BMI was 33.9. Laboratory test showed a BSE of $71 \mathrm{~mm} / \mathrm{h}$, white cell count of $7.0 \times 10^{9} / \mathrm{L}$, and CRP of $12 \mathrm{mg} / \mathrm{L}$.

Differential diagnosis consisted of erosion of the gastric band and symptomatic cicatrical hernia. Gastroscopy showed no abnormalities. On the CT scan, we found an aberrant positioning of the intraabdominal gastric tubing. The tubing entered the upper pole of the left kidney and the tip ended at the kidney's hilus (Figs. 1 and 2). Urine sediment showed no signs of an infection.

Patient was operated on by laparoscopy of the gastric band and tubing was removed.

Postoperative patient suffered from pneumonia with pleural effusion, which was drained and antibiotically treated. On CT scan, there were no intraabdominal abnormalities, especially no urinoma.

After recovery, the patient was dismissed from the hospital, and further follow-up showed no residual signs of pain or pyrosis.

\section{Discussion}

Since the introduction of the adjustable gastric banding by Kuzmak in 1983, this treatment has gained immense popularity in the battle against morbid obesity $[1,2]$. Morbid obese patients have an estimated six- to 12-fold increase in mortality, and medical treatment is often not successful [3]. Due to their weight and associated comorbidity, these patients also have an increase in peri- and postoperative complications. LAGB is considered to be a minimally invasive operative procedure with good results: 


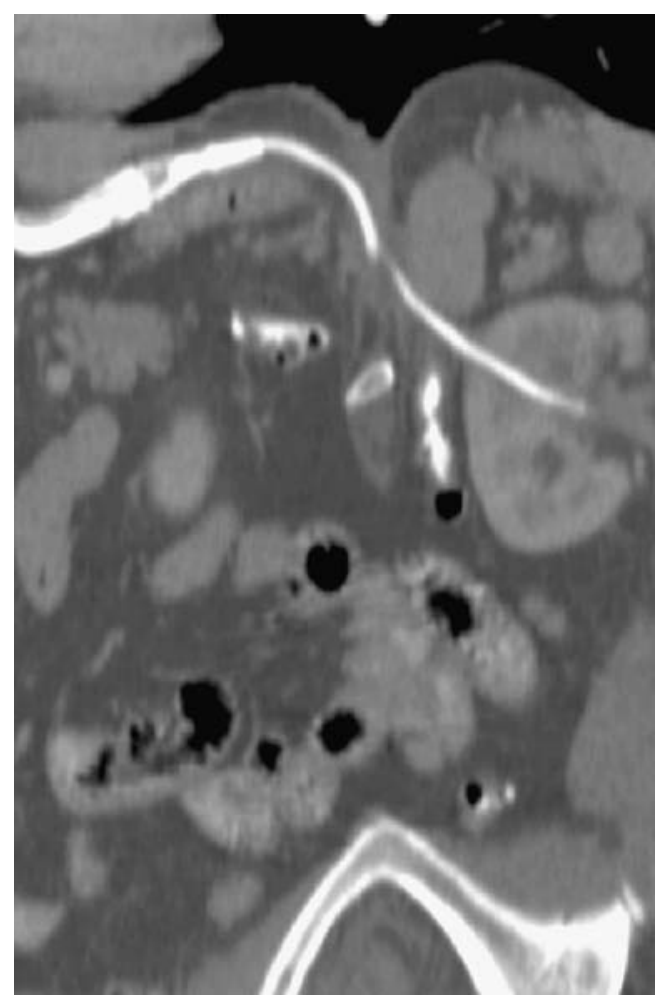

Fig. 1 Reconstruction image of the abdominal CT scan showing intrarenal penetration of the connection tube. The gastric band is seen. Penetration is shown in two directions ending in the hilus of the left kidney

A long-term loss of excess weight of more than $50 \%$ is commonly reported, equal to a decrease in BMI with eight to 12 points [4-9]. In contrast with operations based on malabsorption, the LAGB respects the normal human anatomy and is theoretically reversible $[3,9]$.

Overall, reported complication rates of LAGB ranges from $9 \%$ to $31 \%$ and depend on the time of follow-up [3, 6, 9]. Among the early complications, wound infection is most commonly seen. Wound infection and port site infection can be an early as well as a late complication. Gastric perforation is seen in $0-3 \%$ and always necessitates reoperation $[4,7,9]$. Pulmonary problems (pleural effusion, pneumonia, lung embolism) are also frequently seen.

Late complications mainly originate from either the gastric band or the injection port.

At the site of the gastric band, pouch dilatation is the commonest problem. The incidence of pouch dilatation is $5 \%$ to $17 \%$ according to the time of follow-up $[4-7,9,10]$. Slippage of the band is another late complication, which is partly related to the operation technique. Formerly, the band was positioned transbursally, whereby the lesser sac was penetrated during band implantation. This procedure was abandoned because of the high rate of slippage. The operation technique changed to a suprabursal band position (the pars flaccida technique), resulting in a significant reduction of the incidence of slippage. Still, percentages of $0.6-5 \%$ are reported [5, 10-13]. Migration of the band through the gastric wall has been described in approximately $1 \%$ (range $0.5-3.8 \%$ ) $[4-8,14,15]$. A multitude of case reports exist on this item, varying from a visible gastric band at endoscopy till total band migration and obstruction of the small bowel [16, 17]. Treatment by removal of the band is mandatory and can be done by laparoscopy or endoscopy $[8,14,18]$.

At the site of the injection port leakage, dislocation and infection contribute for the most of the late complications. They all necessitate reoperation. Especially, port site infection can be harsh and end up in surgical removal of the port, leaving the band and tubing intraabdominally.

Rarely, a complication is described originating from the tube connecting the port with the band. To our knowledge, only a few case reports on this subject exist. Daetweiler described a patient who suffered from strangulation of the tubing around the mesenteric root [19]. Zappa described the same complication where the tubing was wrapped around a jejunal loop leading to intermittent obstruction [20]. There are two reports about an intracolonic migration of the tubing [21, 22]. Migration was inflicted by previous treatment of a port infection, as was the case with our patient. The silastic tubing is considered to be inert. Cutting the tubing and leaving it together with the deflated gastric band in the abdomen is an accepted temporary solution for persisting port site infections [9]. A tissue reaction on the tube or band material is not expected, as shown by Lattuada in a histological study [15]. Possibly, a bacterial colonization of the tube could be the eliciting factor of tube migration, though there is no proof of this.

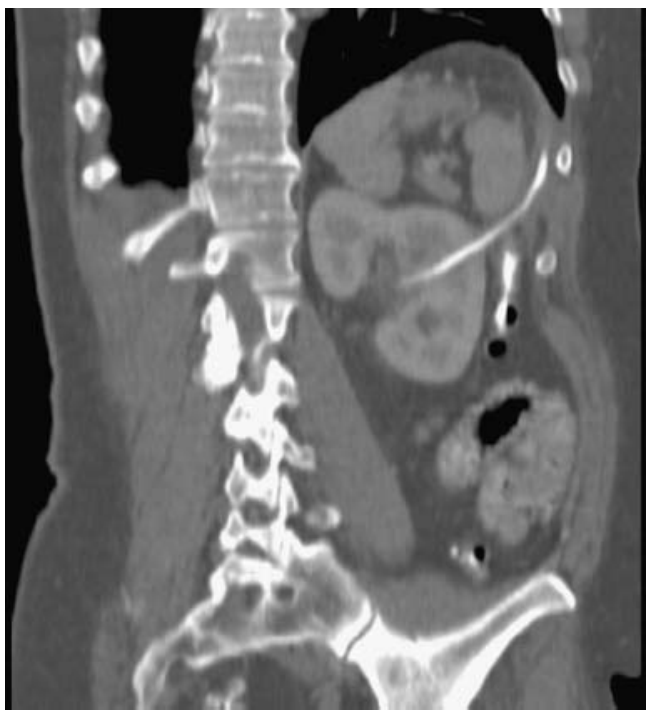

Fig. 2 Reconstruction image of the abdominal CT scan showing intrarenal penetration of the connection tube. A large portion of the tube is seen. Penetration is shown in two directions ending in the hilus of the left kidney 
This is the first report of a tube migration in the hilus of the kidney, which was successfully treated by laparoscopic removal. Although migration of the tube is rare and migration of the band is more likely to occur, one should consider the possibility of either of these when a patient develops gastrointestinal pain some time after placement of a gastric band.

Open Access This article is distributed under the terms of the Creative Commons Attribution Noncommercial License which permits any noncommercial use, distribution, and reproduction in any medium, provided the original author(s) and source are credited.

\section{References}

1. Kuzmak LI. A review of seven years experience with silicone gastric banding. Obes Surg. 1991;1:403-8.

2. Kuzmak LI, Thelmo W, Abramson DL, et al. Reversible adjustable gastric banding. Eur J Surg. 1994;160:571-96.

3. Weiner R, Wagner D, Bockhorn H. Laparoscopic gastric banding for morbid obesity. J Lap Adv Surg Techn. 1999;9:23-30.

4. Doldi SB, Micheletto G, Lattuada E, et al. Adjustable gastric banding: 5-year experience. Obes Surg. 2000;10:171-3.

5. Wolf AM, Kortner B, Kuhlmann HW. Results of bariatric surgery. Int J Obes Relat Metab Disord. 2001;25:S113-4.

6. Coskun H, Bozbora A, Ogunc G, et al. Adjustable gastric banding in a multicenter study in Turkey. Obes Surg. 2003;13:294-6.

7. Micheletto G, Roviaro G, Lattuada E, et al. Adjustable gastric banding for morbid obesity. Our experience. Ann Ital Chir. 2006;77:397-400.

8. Nocca D, Frering V, Gallix B, et al. Migration of adjustable gastric banding from a cohort study of 4,236 patients. Surg Endosc. 2005; 19:947-50.
9. Bueter M, Maroske J, Thalheimer A, et al. Short- and long-term results of laparoscopic gastric banding for morbid obesity. Langenbecks Arch Surg. 2008;393:199-205.

10. Stroh C, Manger T. Komplikationen nach steuerbarem Gastric Banding. Chirurg 2006;77:244-50.

11. Wiesner W, Weber M, Hauser RS, et al. Anterior versus posterior slippage: two different types of eccentric pouch dilatation in patients with adjustable laparoscopic gastric banding. Dig Surg. 2001;18:182-6.

12. Wiener R, Wagner D, Blanco-Engert R, et al. Eine neue Technik zur laparoscopischen Platzierung des steuerbaren Magenbandes. (LAPBand) zur Vermeidung eines Slippage. Chirurg 2002;71:1243-50.

13. Wiener R, Blanco-Engert R, Wiener S, et al. Outcome after laparoscopic adjustable gastric banding - 8 years experience. Obes Surg. 2003;13:427-34.

14. Lattuada E, Zappa MA, Mozzi E, et al. Band erosion following gastric banding: how to treat it. Obes Surg. 2007;17:329-33.

15. Lattuada E, Zappa MA, Mozzi E, et al. Histologic study of tissue reaction to the gastric band: does it contribute to the problem of band erosion? Obes Surg. 2006;16:1155-9.

16. Bueter M, Thalheimer A, Meyer D, et al. Band erosion and passage, causing small bowel obstruction. Obes Surg. 2006;16:1679-82.

17. Egbeare DM, Myers AF, Lawrance RJ. Small bowel obstruction secondary to intragastric erosion and migration of a gastric band. $\mathrm{J}$ Gastrointest Surg. 2007;12:983-4.

18. Niville E, Dams A, Vlasselaers J. Lap-Band erosion: incidence and treatment. Obes Surg. 2001;11:744-7.

19. Daetweiler S, Adamina M, Schöb O. Intractable abdominal pain following laparoscopic adjustable gastric banding. Obes Surg. 2005; $15: 1341-3$.

20. Zappa MA, Lattuada E, Mozzi E, et al. An unusual complication of gastric banding: recurrent small bowel obstruction caused by the connecting tube. Obes Surg. 2006;16:939-41.

21. Hartmann J, Scharfenberg M, Paul M, et al. Intracolonic penetration of the laparoscopic adjustable gastric banding tube. Obes Surg. 2006;16:203-5.

22. Bell BJ, Myers KM, Bour ES. Intracolonic tubing migration: an unusual complication of the silastic adjustable gastric band (LapBand). Surg Obes Relat Dis. 2007;3:486-7. 